\title{
Biosolids-Derived Biochar for Triclosan Removal from Wastewater
}

\author{
Lee K. Kimbell, Yiran Tong, Brooke K. Mayer, and Patrick J. McNamara* ${ }^{*}$ \\ Department of Civil, Construction and Environmental Engineering, Marquette University, Milwaukee, Wisconsin.
}

Received: July 14, $2017 \quad$ Accepted in revised form: September 14, 2017

\begin{abstract}
Micropollutants, including antibiotics, hormones, pharmaceuticals, and personal care products, are discharged into the environment with liquid and solid effluent streams from water resource recovery facilities (WRRFs). The objective of this research was to determine whether biosolids-derived biochar (BS-biochar) could be used as a sorbent in continuous flow-through columns to remove micropollutants as a polishing step for wastewater treatment. Triclosan (TCS) was selected as a representative micropollutant due to frequent detection in liquid effluents, residual biosolids, and surface waters. Bench-scale column experiments were conducted to determine the effect of flow rate and competition due to the presence of other organic micropollutants and inorganic nutrients on TCS adsorption to BS-biochar. TCS removal efficiency was compared in Milli-Q water and secondary wastewater effluent by using two commercial adsorbents: a granular activated carbon and a wood-based biochar. Increased removal of TCS was observed at lower flow rates $\left(2.6 \mathrm{gpm} / \mathrm{ft}^{2}\right)$ compared with higher flow rates $\left(10.3 \mathrm{gpm} / \mathrm{ft}^{2}\right)$. Presence of inorganic nutrients $\left(\mathrm{NH}_{4}{ }^{+}\right.$and $\left.\mathrm{PO}_{4}{ }^{3-}\right)$ and organic micropollutants $17 \beta$-estradiol and sulfamethoxazole decreased adsorption of TCS to BS-biochar. TCS was sorbed to BS-biochar in wastewater, but percent removal decreased in wastewater relative to Milli-Q water. This study demonstrated that BS-biochar can remove TCS from wastewater in continuous flow-through columns, although to a lesser extent than activated carbon. An additional benefit of using BS-biochar is that WRRFs could re-activate biochar on-site by using a pyrolysis reactor.
\end{abstract}

Keywords: adsorption; micropollutants; pyrolysis; water resource recovery facilities

\section{Introduction}

$\mathbf{U}$ RBANIZATION AND OTHER anthropogenic activities have significantly contributed to the discharge of a wide range of organic micropollutants from water resource recovery facilities (WRRFs) into receiving waters (Kolpin et al., 2002; Blair et al., 2013). The contamination of water supplies by organic micropollutants has drawn attention due to associated negative ecological and public health impacts (Kidd et al., 2007; Pal et al., 2014; Reddy et al., 2014). More stringent environmental regulations have helped to mitigate the discharge of traditional contaminants into the environment, including priority pollutants (compounds with known health effects such as herbicides, pesticides, and petroleum hydrocarbons), bacteria, nutrients, and heavy metals (Pitt et al., 1995; Ellis, 2006; Barbosa et al., 2012; Gasperi et al., 2012; Zgheib et al., 2012). However, there is growing concern re-

*Corresponding author: Department of Civil, Construction and Environmental Engineering, Marquette University, $1637 \mathrm{~W}$ Wisconsin Avenue, Milwaukee, WI 53233. Phone: (414)288-2188; E-mail: patrick.mcnamara@mu.edu

${ }^{\dagger}$ Member of AEESP. lated to the introduction of micropollutants into the natural environment and the potential adverse impacts associated with exposure to these compounds, even at very low levels (Gasperi et al., 2012; Inyang and Dickenson, 2015).

Micropollutants are found in many commercial products, such as flame retardants, surfactants, plasticizers, industrial chemicals, and pharmaceuticals and personal care products (Bernhardt et al., 2012; Pal et al., 2014). Micropollutants enter sewer conveyance systems after household use, whereby they are transported to WRRFs. Many micropollutants are recalcitrant to conventional treatment technologies, and they are frequently detected in liquid effluents and residual biosolids (Nowotny et al., 2007; Zerzghi et al., 2010; Manda et al., 2014; Ulrich et al., 2015). Triclosan [TCS, 5-chloro-2-(2,4dichlorophenoxy)-phenol] is a commonly detected antimicrobial micropollutant of concern, and it has been detected in WRRF effluents from 0.02 to $20 \mu \mathrm{g} / \mathrm{L}$ (Foran et al., 2000; Ying and Kookana, 2007). TCS has been linked to negative health effects in a wide variety of organisms (McMurry et al., 1998; Lindström, 2002; Stasinakis et al., 2008). For example, TCS can impair swimming behavior in fathead minnows (Fritsch et al., 2013), cause toxicity in aquatic organisms (particularly algae) (Orvos et al., 2002), and select for antibiotic resistance (Carey and McNamara, 2015, 2016; Carey et al., 2016). 
Although the recent U.S. Food and Drug Administration ban will eliminate TCS from hand soaps, it is still found in a wide range of consumer products, including toothpaste, deodorant, lotion, and surgical scrubs (McMurry et al., 1998; Singer et al., 2002; Heidler and Halden, 2007; Lozano et al., 2013; McNamara and Levy, 2016).

Several advanced tertiary treatment techniques have been investigated for the removal of micropollutants in WRRFs. Treatment processes such as membrane filtration, reverse osmosis, UV treatment, and advanced oxidation processes have proved to be effective for the removal of organic micropollutants, but they are often associated with high infrastructure and operational costs (Kimura et al., 2003; Carballa et al., 2007; Nghiem and Coleman, 2008; Manda et al., 2014). Carbon-based adsorbents (e.g., granular activated carbon [GAC], powdered activated carbon [PAC]) are commonly used in water treatment applications, and previous research has demonstrated TCS removal from aqueous solutions via adsorption to sorbent materials (Behera et al., 2010; Oh and Seo, 2015; Tong et al., 2016). Commercially available activated carbon, commonly produced from bituminous coal or coconut shells, can cost up to $\$ 1,500 /$ ton (Ahmad et al., 2014), whereas the cost for nonactivated biochar is approximately \$246/ton (Inyang and Dickenson, 2015). Thus, replacing or augmenting traditional activated carbon adsorbents with biochar could greatly reduce treatment costs if additional costs for activating biochar are reasonable (Ahmad et al., 2012; Inyang and Dickenson, 2015).

Biochar is a porous, carbon-rich product with a high surface area to volume ratio, and it is produced via pyrolysis (thermochemical decomposition in the absence of oxygen) or the incomplete combustion of biomass (Agrafioti et al., 2013; Tan et al., 2015; McNamara et al., 2016; Thompson et al., 2016). Biochar has been growing in popularity in the past few decades as a soil amendment for agricultural improvements and carbon sequestration, and it has also demonstrated great potential as an adsorbent to remove pollutants from aqueous solutions (Kearns et al., 2014; Mohan et al., 2014; Qian et al., 2015; Rajapaksha et al., 2016). Biochar can be produced from a variety of materials, including agricultural residues, animal litters, wood biomass, and sewage sludge or biosolids (Mohan et al., 2014; Tan et al., 2015; Xie et al., 2015). The biosolids generated at WRRFs represent a carbon-rich residual solid product that could be readily transformed into an adsorbent. Further, biochar production from sewage sludge biosolids could reduce the volume of solids produced by WRRFs (and thus the costs of handling) while also generating a value-added product, that is, an adsorbent to remove contaminants from water (Yu and Zhong, 2006; Smith et al., 2009; Roberts et al., 2010; Oleszczuk et al., 2012; Hadi et al., 2015).

Previous research employing batch experiments has demonstrated that biosolids-derived biochar (BS-biochar) is a suitable sorbent for micropollutants (Otero et al., 2003; Smith et al., 2009; Yao et al., 2013; Tong et al., 2016). Specifically, previous work demonstrated via batch sorption experiments that BS-biochar was an effective sorbent for TCS removal from water and (Tong et al., 2016). Tong et al. (2016) revealed that BS-biochar was as effective as activated carbon at removing TCS at environmentally relevant concentrations $(20 \mu \mathrm{g} / \mathrm{L})$. This research also revealed, however, that organic matter impacted TCS removal, implying that limitations likely apply to using BS-biochar at a WRRF.
There is limited information regarding the application of BSbiochar in systems for sorbing organic contaminants from drinking water, municipal wastewater, or potable applications at scales beyond batch adsorption testing. Column studies performed with wood-derived biochars have demonstrated removal of micropollutants such as bisphenol-A (BPA), atrazine, $17 \alpha$-ethinylestradiol, sulfamethoxazole (SMX), and ibuprofen (Jung et al., 2013; Ulrich et al., 2015). In addition, previous column studies have reported that Freundlich parameters differed from those based on batchscale isotherm tests, and that adsorption parameters obtained from column tests provided more realistic information for real-world applications (Schindeman et al., 2012).

The objective of this study was to determine the efficacy of BS-biochar adsorption for TCS removal during continuousflow column experiments. Bench-scale column experiments were conducted to determine the effect of flow rate, competition due to the presence of other organic micropollutants or inorganic nutrients, and competition from a complex secondary wastewater matrix on TCS removal. TCS removal using BS-biochar was also compared with two commercial adsorbents: a commercial GAC and a pine wood-derived biochar adsorbent. Characterization of biochar and activated carbon adsorbents was performed to better understand the physical and chemical interactions governing TCS adsorption.

\section{Experimental Protocols}

\section{Adsorbents}

Feedstock for the BS-biochar in this study was Milorganite $^{\circledR}$, a heat-dried blend of waste activated sludge and anaerobically digested primary solids, produced by the Milwaukee Metropolitan Sewerage District (Milwaukee, WI). The feedstock was pyrolyzed to produce biochar by placing $\sim 50$ g of Milorganite into a 250-mL flask, purging with argon gas for $15 \mathrm{~min}$, capping with aluminum foil, and heating in a muffle furnace for $60 \mathrm{~min}$ at $600^{\circ} \mathrm{C}$. This method of pyrolysis has been previously described in studies pyrolyzing Milorganite and other forms of biomass to produce biochar ( $\mathrm{CaO}$ and Harris, 2010; Ahmad et al., 2012; Agrafioti et al., 2013; Carey et al., 2015; Hoffman et al., 2016; Ross et al., 2016; Tong et al., 2016). The biochar was cooled in a desiccator to room temperature before conditioning for adsorption tests.

BS-biochar was washed with Milli-Q ${ }^{\circledR}$ (Billerica, MA) water to remove residual surface impurities and ash before acid washing. The acid conditioning consisted of mixing $1 \mathrm{~g}$ biochar per $10 \mathrm{~mL} 1 \mathrm{~N} \mathrm{HCl}$ in a sealed $1 \mathrm{~L}$ flask on a shaker table at $150 \mathrm{rpm}$ for $24 \mathrm{~h}$. The biochar slurry was filtered with Whatman $^{\circledR}$ (Ann Arbor, MI) $0.7 \mu \mathrm{m}$ glass fiber filters via vacuum filtration. The recovered biochar was rinsed three or more times with Milli-Q water to remove ash and the remaining acid before being dried in a $103^{\circ} \mathrm{C}$ oven and stored in a desiccator for use in adsorption experiments.

Adsorption experiments were also conducted with one pine wood-based biochar produced by Biochar Now in Berthoud, CO (BN-biochar) and one GAC produced by Calgon Carbon, Pittsburgh, PA (Calgon Filtrasorb ${ }^{\circledR}$ 300) (CF300AC). The wood-based biochar and coal-based activated carbon were used to compare TCS adsorption with that of the BS-biochar. The BN-biochar was subjected to the same acid washing protocol as the BS-biochar. The CF300-AC was not 
modified before use in column adsorption experiments, but it was activated by the manufacturer using steam activation.

\section{Column adsorption tests}

Column adsorption tests were conducted to determine the removal of TCS from Milli-Q water and wastewater solutions by using BS-biochar and two commercial adsorbents under continuous flow conditions. All glassware was silanized by using $5 \%$ by volume dichlorodimethylsilane (99.5\%; Sigma Aldrich, St. Louis, MO) and $95 \%$ by volume heptane (99\%; Sigma Aldrich) solution to prevent chemicals from adsorbing onto the glass surface. TCS (97\%; Sigma Aldrich) was predissolved in high-performance liquid chromatography (HPLC)grade methanol ( $99 \%$; Sigma Aldrich) and stored at $4^{\circ} \mathrm{C}$ for use as stock solution. The volumetric ratio of methanol/TCS stock to water was $<0.5 \%$ for all adsorption tests, which has no cosolvent effects (Schwarzenbach et al., 2003; Tong et al., 2016).

Downflow fixed-bed column experiments were conducted by using $11 \mathrm{~mm}$ inner diameter, $60 \mathrm{~cm}$ long glass columns (Ace Glass Incorporated, Vineland, NJ). Glass columns were packed with biochar or activated carbon adsorbents (bed depth $\sim 5^{\prime \prime}$ or $12.7 \mathrm{~cm}$ ) between two supporting layers of glass wool and glass beads. The adsorption columns were operated at room temperature and fed by using a peristaltic pump (Syringe Pump NE-9000G; New Era Pump Systems, Inc., Farmingdale, NY) programmed at a constant volumetric flow rate. Column influent and effluent samples were collected at different time intervals in $4 \mathrm{~mL}$ amber vials and analyzed for the target constituents (i.e., TCS).

Reproducibility of column experiments. Initial TCS adsorption experiments were conducted in triplicate to determine reproducibility and variation among identical column adsorption experiments. Breakthrough curves for each treatment group demonstrated high reproducibility and demonstrated similar trends in TCS removal for the duration of the column studies (Supplementary Fig. S1 and Supplementary Table S1). Due to the low variability among replicates, individual column experiments were conducted for the adsorption experiments.

Effect of flow rate on TCS adsorption. Column adsorption experiments were conducted to determine the impact of flow rate on TCS adsorption to BS-biochar. Volumetric flow rates were controlled by using a peristaltic pump, and ranged from 10 to $40 \mathrm{~mL} / \mathrm{min}$, which is equivalent to a hydraulic loading rate of $2.6-10.3 \mathrm{gpm} / \mathrm{ft}^{2}\left(106-420 \mathrm{Lpm} / \mathrm{m}^{2}\right)$. Flow rate adsorption experiments were conducted at $\mathrm{pH} 7$, and TCS was added at a concentration of $\sim 500 \mu \mathrm{g} / \mathrm{L}$ for flow rate experiments. TCS was added at much higher levels than environmental concentrations for improved quantification of removal efficiency during adsorption experiments. It is noted that these higher experimental concentrations could result in greater removal of TCS than observed in real wastewaters due to the stronger driving force for sorption at higher concentrations. Results should be interpreted to determine relative performance of different sorbents (i.e., BS-biochar vs. activated carbon vs. BN-biochar) and relative impact of different water quality parameters (e.g., role of competition from micropollutants).
Effect of organic micropollutant competition. Micropollutant competition experiments were performed to assess the impact on TCS adsorption to BS-biochar by spiking $17 \beta$-estradiol (E2) and SMX with TCS into Milli-Q water adjusted to $\mathrm{pH} 7$. These micropollutants were selected due to their frequent detection in surface waters and WRRF effluents (McAvoy et al., 2002; Hoffman et al., 2016; Shimabuku et al., 2016; Tohidi and Cai, 2017). In addition, TCS has a pKa of 8.14 (Behera et al., 2010) and exists in both the neutral and anionic forms in solutions near neutral $\mathrm{pH}$. E2 has a pKa above 10 and was added to provide competition for the neutral form. SMX has a pKa of 5.7 and is anionic in the $\mathrm{pH}$ range of most natural aquatic systems (Shimabuku et al., 2016). Similar to TCS, E2 (98\%; Sigma Aldrich) and SMX (Sigma Aldrich) were predissolved in HPLC-grade methanol and stored at $4{ }^{\circ} \mathrm{C}$ for use as stock solutions. E2, SMX, and TCS were each added at a concentration of $\sim 350 \mu \mathrm{g} / \mathrm{L}$ for the micropollutant competition experiments.

Effect of inorganic nutrient competition. Impact of the inorganic nutrients ammonium $\left(\mathrm{NH}_{4}{ }^{+}\right)$and phosphate $\left(\mathrm{PO}_{4}{ }^{3-}\right)$ on TCS adsorption to BS-biochar was investigated. Nutrients are present in wastewater streams at much higher concentrations than micropollutants, and these ionic species could potentially compete for adsorption sites on the biochar surface. In these experiments, $\mathrm{NH}_{4}{ }^{+}$was added as $\mathrm{NH}_{4} \mathrm{Cl}(99.8 \%$; Fisher Scientific, Pittsburgh, $\mathrm{PA}$ ) at $50 \mathrm{mg} / \mathrm{L}$ as $\mathrm{NH}_{3}-\mathrm{N}_{\text {and }} \mathrm{PO}_{4}{ }^{3-}$ was added as $\mathrm{K}_{2} \mathrm{HPO}_{4}\left(99.2 \%\right.$; Fisher Scientific) at $1 \mathrm{mg} / \mathrm{L}$ as $\mathrm{PO}_{4^{-}}$ $\mathrm{P}$ to Milli-Q water solutions. Nutrient concentrations were chosen to simulate a wastewater with a high nutrient content that would also contain micropollutants such as anaerobic membrane bioreactor effluent (Seib et al., 2016). Secondary effluent wastewater would likely contain lower levels of nutrients and thus less competition for adsorption sites due to nutrients in solution (Tan et al., 2015). TCS was added at a concentration of $\sim 350 \mu \mathrm{g} / \mathrm{L}$ for the nutrient competition experiments.

TCS removal in secondary wastewater effluent. To investigate TCS adsorption to BS-biochar in real-world wastewater matrices, municipal secondary-treated wastewater effluent samples were obtained from Jones Island Water Reclamation Facility (Milwaukee, WI). Milli-Q and wastewater adsorption experiments were conducted with BSbiochar, BN-biochar, and CF300-AC to compare the removal of TCS by using a variety of carbonaceous adsorbents. Water quality parameters, including $\mathrm{pH}$, conductivity, chemical oxygen demand (COD), total organic carbon (TOC), $\mathrm{NH}_{3}-\mathrm{N}$, $\mathrm{PO}_{4}-\mathrm{P}$, and solids fractions including total solids, volatile solids, fixed solids, total suspended solids, volatile suspended solids, fixed suspended solids, total dissolved solids, volatile dissolved solids, and fixed dissolved solids, were quantified. Conductivity and $\mathrm{pH}$ were measured with a Thermo Scientific Orion STAR probe, and they were measured over the course of the adsorption experiments at time $(t)=0,60,300,1,440$, and 2,880 min of operation. $\mathrm{COD}, \mathrm{TOC}, \mathrm{NH}_{3}-\mathrm{N}, \mathrm{PO}_{4}-\mathrm{P}$, and solids fractions were measured according to Standard Methods for secondary wastewater effluent characterization (American Public Health Association [APHA], 1975). Approximately $500 \mu \mathrm{g} / \mathrm{L}$ TCS stock solution was added to the wastewater effluent. To investigate adhesion of TCS to solids in the wastewater matrix (removal not attributed to biochar sorption), 
an adsorption column without biochar was used as a control. The background TCS concentration in the secondary wastewater effluent was below detection limit $(<2 \mu \mathrm{g} / \mathrm{L})$.

\section{Micropollutant analysis via liquid chromatography-mass spectrometry}

At each sampling time, $\sim 4 \mathrm{~mL}$ of column effluent were collected in a glass amber vial for subsequent micropollutant analysis. Water samples were stored at $4^{\circ} \mathrm{C}$ for $1-2$ days before being mixed with HPLC grade methanol (50:50) and filtered through $0.45 \mu \mathrm{m}$ polytetrafluoro-ethylene filters into $2 \mathrm{~mL}$ amber liquid chromatography-mass spectrometry (LC-MS) vials. Aqueous phase E2, TCS, and SMX were measured with LC-MS (Shimadzu Corporation; LCMS-2020) as previously described (Tong et al., 2017).

Briefly, a binary gradient of Milli-Q water and $100 \%$ HPLC-grade methanol was used as the eluent for LC-MS analysis. The gradient began at $80 \%$ methanol, raised to $100 \%$ methanol at $8 \mathrm{~min}$, ramped down to $80 \%$ methanol from 8 to $9 \mathrm{~min}$, and remained at $80 \%$ methanol to $13 \mathrm{~min}$ to allow column re-equilibration. The eluent flow rate was $0.4 \mathrm{~mL} / \mathrm{min}$. Sample injections of $20 \mu \mathrm{L}$ were passed through a Phenomenex ${ }^{\circledR}$ (Torrance, CA) Luna 3u C18 reverse-phase column $(150 \times 3 \mathrm{~mm}, 100 \AA$ pore size $)$. TCS and E2 were detected via mass spectrometry with negative electrospray ionization (ESI-), at mass-to-charge $(\mathrm{m} / \mathrm{z})$ ratios of 287 and 271 , respectively. SMX was detected via mass spectrometry with positive ESI (ESI+), at a $(\mathrm{m} / \mathrm{z})$ of 252 . Identification of target analytes was based on the presence of parent compounds eluting from the column at the same retention time as standards. Quantification was based on the linear regression analysis of sample peak area to that of at least a five-point standard curve developed for each compound. Quantification limits for TCS, E2, and SMX based on a signal-to-noise ratio of $10: 1$ were 2,7 , and $10 \mu \mathrm{g} / \mathrm{L}$, respectively.

Recovery of TCS from secondary wastewater effluent was verified through the addition of an internal standard before LCMS analysis. The internal standard used in this study was TCS $\left({ }^{13} \mathrm{C}_{12}, 99 \%\right.$; Cambridge Isotope Laboratories, Inc., Andover, MA). A known amount of TCS internal standard was added to every sample, standard, and blank before analysis. A calibration curve was constructed for known concentrations of internal standard versus the ratio of target analyte (TCS) response to the internal standard response for each sample.

\section{Adsorption calculations and statistical analyses}

Adsorption experiments were compared by the number of bed volumes treated before mass breakthrough, defined as $C_{\mathrm{e}}=0.05 C_{\mathrm{o}}$ (Schwarzenbach et al., 2003; American Society of Testing Materials [ASTM], 2013). $C_{\mathrm{e}}$ denotes the concentration of TCS in the effluent, and $C_{\mathrm{o}}$ denotes the influent concentration of TCS. The mass of TCS removed after 2,000 bed volumes treated through each column was also quantified and used to compare the adsorption experiments. This number of bed volumes was chosen for comparison due to observed decreases in performance of columns after this time (reduced flow rates due to clogging) during experiments using actual wastewater. Other column parameters determined for each column adsorption experiment included empty bed contact time (EBCT) and carbon usage rate (CUR). EBCT is a measure of the time during which the water flowing through the column was in contact with the treatment medium (i.e., BS-biochar), and CUR is the rate at which the carbon was exhausted in the column during treatment.

GraphPad Prism 7.02 was used for statistical analysis, including nonlinear analysis of breakthrough curves. Nonlinear regression of column adsorption data was fit by using saturation function models to obtain best-fit model parameters, $C_{\mathrm{e}} / C_{\mathrm{o}}$ and $\mathrm{Kc}$, for comparing experimental results. $C_{\mathrm{e}} / C_{\mathrm{o}}$ represents how close the effluent concentration $\left(C_{\mathrm{e}}\right)$ is to initial concentration $\left(C_{\mathrm{o}}\right)$. A $C_{\mathrm{e}} / C_{\mathrm{o}}$ value of 1 would mean that the column was fully exhausted and none of the sorbate was being removed by the sorbent. $C_{\mathrm{e}} / C_{\mathrm{o}}$ max values did not reach 1 during the course of the experiments, which indicates that the adsorbent did not reach exhaustion. Previous studies have reported that exhaustion of GAC filters for trace organic contaminants is substantially longer than for natural organic matter (NOM), and that methods appropriate for estimating GAC replacement frequency for NOM removal are not directly applicable in regards to trace organic contaminant removal (Schindeman et al., 2012). Similarly, several studies have reported that quantitative results obtained from rapid small-scale column tests and pilot-scale studies for trace organic contaminants can significantly overestimate GAC service life (Crittenden et al., 1991; Knappe et al., 1997). Due to this, the mass of TCS removed after 2,000 bed volumes treated through each column was quantified and used to compare the adsorption experiments. In addition, this number of bed volumes was chosen for comparison due to observed decreases in performance of columns after this time (reduced flow rates due to clogging) during laboratory wastewater adsorption experiments. Kc was defined as the number of bed volumes passed through the column when the $C_{\mathrm{e}} / C_{\mathrm{o}}$ value equals half of the observed $C_{\mathrm{e}} / C_{\mathrm{o}}$ max. Saturation models assume that a limited number of adsorption sites exist on an adsorbent surface and that each site can hold at most one molecule of adsorbate.

\section{Characterization of adsorbents}

Surface area analysis. Biochar and activated carbonspecific surface areas were measured via $\mathrm{N}_{2}$ gas adsorption at $77 \mathrm{~K}$ by using a Brunauer-Emmett-Teller (BET) automated surface analysis instrument, Autosorb iQ2 (Quantachrome Instruments, Boynton Beach, FL). MultiPoint BET surface area analysis results are reported in $\mathrm{m}^{2} / \mathrm{g}$ of adsorbent. The average pore radius was determined and is reported in units of Angstroms $(\AA)$. Total pore volume was determined for each adsorbent, in addition to the total micropore volume as determined by the t-method (Rozada et al., 2005; Zhu et al., 2014; Shimabuku et al., 2016). Pore volume data for adsorbents are reported in $\mathrm{cm}^{3} / \mathrm{g}$ of adsorbent.

Fourier transform infrared spectroscopy analysis. Fourier transform infrared spectroscopy (FTIR) was used to analyze surface functional groups on the adsorbent surfaces. A Shimadzu IR Tracer 100 (Shimadzu Corporation, MD) was used to investigate biochar and activated carbon surface functional groups. FTIR spectral analyses can be used to help elucidate the role of functional groups in the adsorption of molecules from aqueous solutions (Ahmad et al., 2014; Hadi et al., 2015). FTIR spectra were recorded from 4,000 to $150 \mathrm{~cm}^{-1}$ wavelengths and plotted versus percent transmittance. 
Scanning electron microscopy imaging. Scanning electron microscopy (SEM) was used to compare surface morphology of the adsorbents. Granular biochar and activated carbon were dried in a desiccator and adhered to an SEM specimen mount with carbon tape. The surface morphology was observed via JEOL JSM-6510LV SEM (JEOL USA, Inc., MA) at an accelerating voltage of $15 \mathrm{kV}$ and magnifications ranging from $20 \times$ to $1,000 \times$.

\section{Results and Discussion}

\section{Impact of flow rate on TCS removal}

TCS sorption to BS-biochar increased as flow rate decreased and EBCT increased (Fig. 1). Flow rates ranged from 10 to $40 \mathrm{~mL} / \mathrm{min}$ (surface loading rate of $2.6-10.3 \mathrm{gpm} / \mathrm{ft}^{2}$ ). SLRs for GAC filters at municipal water treatment plants typically range from 2 to $10 \mathrm{gpm} / \mathrm{ft}^{2}$ (Environmental Protection Agency [EPA], 2017). At the lower range of flow rates tested, an increase in bed volumes treated before reaching mass breakthrough, an increase in Kc values, and a larger fraction of influent TCS removed after 2,000 bed volumes were observed (Table 1). In addition, $C_{\mathrm{e}} / C_{\mathrm{o}}$ max values ranged from 0.72 to 0.80 for higher flow rate experiments, indicating decreased TCS removal performance compared with low flow rate tests.

At lower flowrates, longer contact time between adsorbent and adsorbate molecules resulted in increased adsorption of TCS from solution. Increased time to reach breakthrough for lower flow rates reduced the CUR (less BS-biochar mass exhausted per volume treated), which allowed for longer filter runs with higher removal efficiency. The reduction in TCS removal for higher flow rates was likely due to a shorter EBCT, which reduced the contact time between the TCS molecules and the biochar surface. The EBCT is a crucial design parameter when sizing carbon filters for WRRF treatment, with longer EBCTs typically leading to improved retention of adsorbates and higher contaminant removal efficiency (Crittenden et al., 1991; Schindeman et al., 2012; Zietzschmann et al., 2014). However, maximizing EBCT for increased contaminant adsorption means increasing the size of filter beds and/or

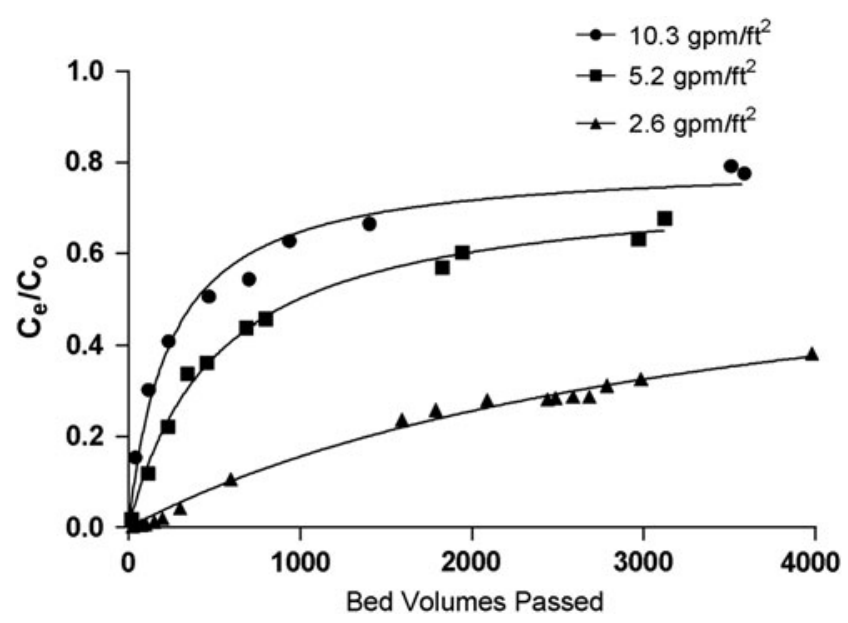

FIG. 1. Impact of flow rate. Lower flow rate improved TCS removal during column experiments. Experiments were conducted at $\mathrm{pH} \mathrm{7,} \mathrm{and} \mathrm{TCS} \mathrm{was} \mathrm{added} \mathrm{to} \mathrm{Milli-Q} \mathrm{water} \mathrm{at}$ $\sim 500 \mu \mathrm{g} / \mathrm{L}$. TCS, triclosan. retention time, which can limit operational flexibility where specific volumetric flows must be treated.

\section{Impact of competition from organic micropollutants on TCS removal}

BS-biochar simultaneously removed all three micropollutants to varying degrees; however, removal of TCS decreased in the presence of E2 and SMX in comparison to TCS removal without competition from other micropollutants (Fig. 2). With competition from E2 and SMX, the mass of TCS removed decreased. Although TCS adsorption was decreased considerably (i.e., 1,330 to $517 \mu \mathrm{g} / \mathrm{g}$ ), similar total micropollutant removal $(1,320 \mu \mathrm{g} / \mathrm{g})$ was observed after 2,000 bed volumes compared with single solute (TCS) experiments. Of the three micropollutants studied, TCS had the greatest amount of sorption in terms of mass sorbed and moles sorbed $(517 \mu \mathrm{g} / \mathrm{g}$ for TCS vs. 300 and $500 \mu \mathrm{g} / \mathrm{g}$ for SMX and E2, respectively; $1786 \mu$ moles/g for TCS vs. 1,687 and $1,184 \mu$ moles/g for SMX and E2, respectively).

Breakthrough curves observed for the micropollutants in Fig. 2 suggest that TCS removal was decreased likely due to direct competition for adsorption sites on the BS-biochar surface by E2 and SMX molecules. Adsorption mechanisms such as hydrogen bonding and $\pi-\pi$ interactions between aromatic rings on the adsorbent surface and adsorbate $\pi$-electrons likely contributed to adsorption of all organic micropollutants in solution (Monsalvo et al., 2011; Lei et al., 2013; Tong et al., 2016), thereby decreasing the fraction of TCS removed by BS-biochar. Similarly, Jung et al. (2013) reported competitive adsorption effects between endocrine disrupting compounds (including SMX and BPA) for adsorption sites on PAC and biochar derived from loblolly pine chips (Jung et al., 2013).

Competition between micropollutants for limited adsorption sites available on adsorbent surfaces is also influenced by factors such as octanol-water partitioning coefficients (Kow), bulk solution $\mathrm{pH}$, and dissociation constants $(\mathrm{pKa})$ for each micropollutant (Nam et al., 2014; Tong et al., 2016). The similarity in the breakthrough curves for E2 and TCS suggests that BS-biochar has an increased affinity for these more hydrophobic compounds. The log Kow values for the micropollutants tested are 4.01 for E2 (Blánquez and Guieysse, 2008) and 4.76 for TCS (Behera et al., 2010), compared with 0.68 for SMX (Nam et al., 2014). The smaller log Kow of SMX indicates the tendency of the compound to remain in the aqueous phase, which supports the result of less removal of SMX compared with E2 and TCS. In addition, the pKa of SMX is 5.7 (Nam et al., 2014) compared with 8.14 for TCS (Behera et al., 2010), which indicates that a larger fraction of SMX molecules would be negatively charged in solutions at neutral $\mathrm{pH}$ ranges. The net negative surface charge of BSbiochar in solutions with neutral $\mathrm{pH}$ may also contribute to a reduced affinity for adsorption of anionic organic contaminants such as SMX compared with TCS (Shimabuku et al., 2016; Thompson et al., 2016).

\section{Impact of competition from inorganic nutrients on TCS removal}

Presence of inorganic nutrients (ammonium and phosphate) decreased TCS removal (Fig. 3). Mass breakthrough of TCS in column effluent was reduced by 330 bed volumes 
Table 1. Results From COLUmn AdSOrption Experiments

\begin{tabular}{|c|c|c|c|c|c|c|}
\hline Experiment & $\begin{array}{c}E B C T \\
\text { (minutes) }\end{array}$ & $\begin{array}{l}\text { Mass } \\
\text { breakthrough } \\
\text { bed volume }\end{array}$ & $\begin{array}{c}\text { TCS mass removed } \\
\text { after } 2,000 \text { bed } \\
\text { volumes }(\mu \mathrm{g} / \mathrm{g})\end{array}$ & $K c$ & $C_{e} / C_{o} \operatorname{Max}$ & $R^{2}$ \\
\hline \multicolumn{7}{|c|}{ Milli-Q (MQ) experiments } \\
\hline $2.6 \mathrm{gpm} / \mathrm{ft}^{2}$ & 1.2 & 1,371 & 1,310 & 3,583 & 0.72 & 0.99 \\
\hline $5.2 \mathrm{gpm} / \mathrm{ft}^{2}$ & 0.6 & 1,013 & 896 & 519 & 0.76 & 0.99 \\
\hline $10.3 \mathrm{gpm} / \mathrm{ft}^{2}$ & 0.3 & 450 & 700 & 240 & 0.80 & 0.97 \\
\hline Micropollutants & 1.2 & 675 & 517 & 110 & 0.40 & 0.87 \\
\hline Nutrients & 1.2 & 450 & 450 & 144 & 0.51 & 0.81 \\
\hline BS-biochar & 1.2 & 780 & 1,330 & 3,711 & 0.74 & 0.99 \\
\hline BN-biochar & 1.2 & 219 & 280 & 40 & 0.89 & 0.98 \\
\hline CF300-AC & 1.2 & 1,404 & 1,400 & 112 & 0.12 & 0.92 \\
\hline \multicolumn{7}{|c|}{ Wastewater (WW) experiments } \\
\hline BS-biochar & 1.2 & 620 & 667 & 762 & 0.75 & 0.98 \\
\hline BN-biochar & 1.2 & 250 & 520 & 69 & 0.70 & 0.99 \\
\hline CF300-AC & 1.2 & 1,643 & 1,070 & 1,340 & 0.19 & 0.58 \\
\hline
\end{tabular}

All experiments were operated at a flow rate of $2.6 \mathrm{gpm} / \mathrm{ft}^{2}$ unless otherwise noted.

EBCT, empty bed contact time; TCS, triclosan; $C_{\mathrm{e}}$, effluent concentration; $C_{\mathrm{o}}$, influent concentration; Kc, number of bed volumes passed through column when $C_{\mathrm{e}} / C_{\mathrm{o}}$ equals half observed $C_{\mathrm{e}} / C_{\mathrm{o}}$ max; CF300-AC, activated carbon; BS-biochar, biosolids-derived biochar; BNbiochar, pine wood-derived biochar.

in the presence of inorganic nutrients, indicating competition between nutrients and TCS for adsorption sites. Phosphate ions in solution likely played a larger role in competitive adsorption due to being negatively charged (similar to TCS).

$C_{\mathrm{e}} / C_{\mathrm{o}}$ max and $\mathrm{Kc}$ values for TCS with inorganic nutrients decreased compared with TCS only (Table 1), which indicates suppressed adsorptive capacity for TCS as inorganic nutrient ions interfered with TCS adsorption to BS-biochar. The Kc value decreased by $96 \%$ with the co-presence of inorganic nutrients in solution, indicating shorter column operation time to reach saturation of the BS-biochar filter bed. Although removal of TCS was suppressed due to the co-presence of $\mathrm{NH}_{4}^{+}$ and $\mathrm{PO}_{4}{ }^{3-}$ ions in solution, the BS-biochar did not exhibit a strong affinity for adsorption of ionic nutrient compounds (Supplementary Fig. S2). The reduction in TCS adsorption

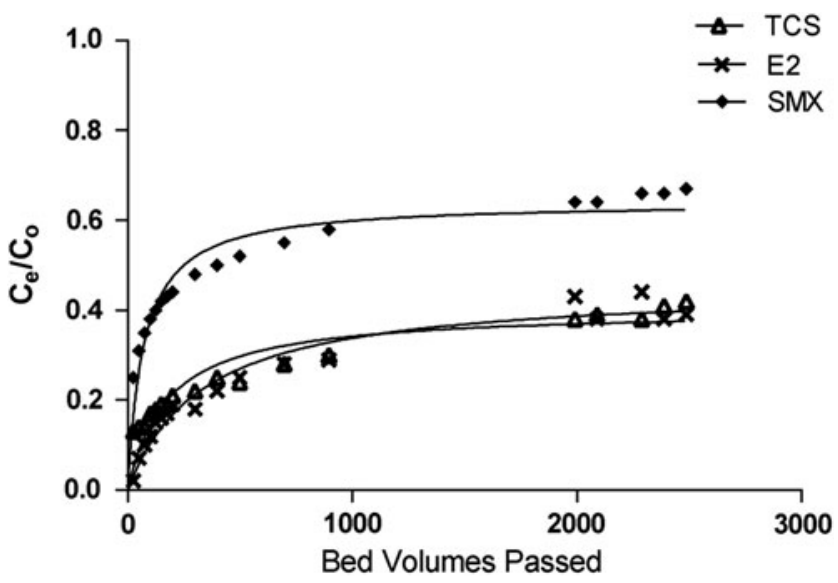

FIG. 2. Impact of micropollutant competition. Competition from organic micropollutants decreased TCS removal. Experiments were conducted at $\mathrm{pH} 7$ at a loading rate of $2.6 \mathrm{gpm} / \mathrm{ft}^{2}$. Micropollutants (E2, TCS, SMX) were added to Milli-Q water at $\sim 350 \mu \mathrm{g} / \mathrm{L}$ each. E2, $17 \beta$-estradiol; SMX, sulfamethoxazole. could be attributed to the physical blocking of surface adsorption sites by the nutrient ions (Yao et al., 2013). Nutrients in solution were present at much higher concentrations compared with TCS, and they likely blocked molecular interactions between TCS molecules and adsorption sites on the BS-biochar surface.

Previous research has demonstrated the ability of biochars from various feedstocks to sorb nutrients such as phosphate and ammonium from water and wastewater solutions (Cao and Harris, 2010; Reddy et al., 2014; Ulrich et al., 2015). In particular, recent research has demonstrated the ability of BSbiochar activated with $\mathrm{KOH}$ to sorb up to $5.8 \mathrm{mg} / \mathrm{g} \mathrm{NH}_{3}-\mathrm{N}$ from aqueous solutions (Carey et al., 2015). Similarly, biochar derived from anaerobically digested sugar beet tailings has demonstrated removal of more than $73 \%$ of phosphate from aqueous solutions containing phosphate from 15 to

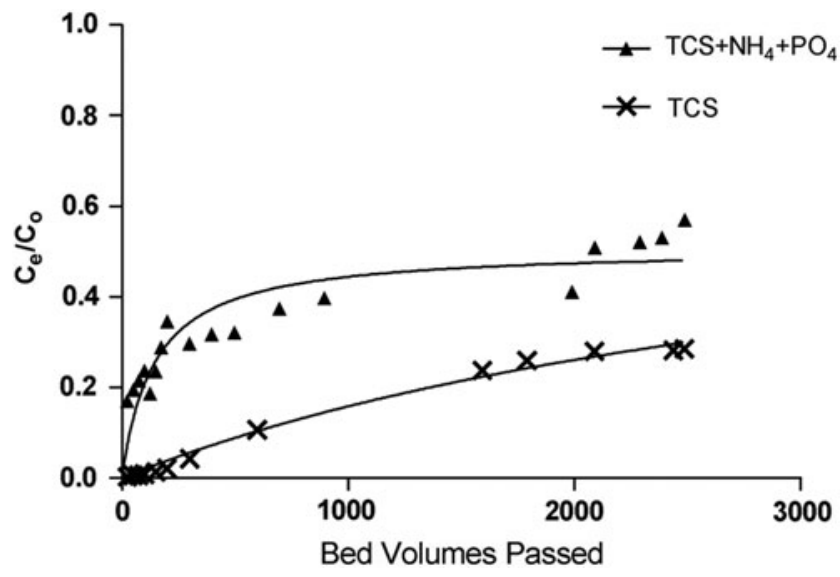

FIG. 3. Impact of nutrient competition. Inorganic nutrient competition decreased TCS removal. Experiments were conducted at $\mathrm{pH} 7$ with a loading rate of $2.6 \mathrm{gpm} / \mathrm{ft}^{2}$. Nutrients were added to solution at concentrations of $\sim 1 \mathrm{mg} / \mathrm{L}$ as $\mathrm{PO}_{4}-\mathrm{P}$ and $50 \mathrm{mg} / \mathrm{L}$ as $\mathrm{NH}_{3}-\mathrm{N}$. TCS was added to Milli-Q water at $\sim 350 \mu \mathrm{g} / \mathrm{L}$. 


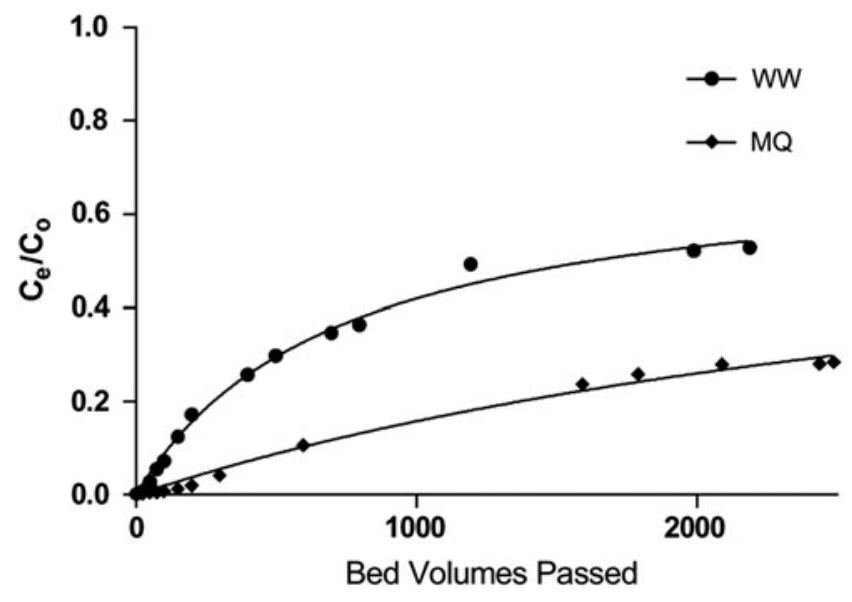

FIG. 4. Impact of secondary WW matrix on TCS removal. Experiments were conducted at $\mathrm{pH} 7$ with a loading rate of $2.6 \mathrm{gpm} / \mathrm{ft}^{2}$ in either MQ water or WW. TCS stock solution was added at $\sim 500 \mu \mathrm{g} / \mathrm{L}$. WW, wastewater; MQ, Milli-Q.

$640 \mathrm{mg} / \mathrm{L}$ (Yao et al., 2011). Although these studies demonstrate potential for biochar to be used for nutrient sorption, biochar is extremely variable and can be altered based on feedstock, pyrolysis temperature, and treatments. Deeper mechanistic studies that analyze functional groups and surface charge need to be conducted to elucidate why biochars sorb nutrients to different extents.

Impact of secondary-treated wastewater matrix on TCS removal. The presence of organic matter and other constituents in the wastewater matrix decreased TCS removal (Fig. 4). Mass breakthrough occurred more rapidly, and the TCS mass removed was reduced by $50 \%$ in wastewater relative to Milli-Q (Table 1). Similarly, the Kc was reduced by $78 \%$ in wastewater compared with Milli-Q. The larger Kc value for TCS removal from Milli-Q water suggests that more bed volumes could be treated before reaching exhaustion of the BS-biochar filter bed, presumably due to the lack of competing organic matter and other constituents compared with wastewater effluent.

Presence of organic matter along with trace organic contaminants in water causes competitive adsorption effects, including direct site competition and pore blockage, which can fluctuate with varying levels of organic matter (Behera et al., 2010; Uchimiya et al., 2010; Tan et al., 2015). Direct site competition is considered the strongest factor in organic matter competition because it reduces the equilibrium capacity of adsorption sites for trace organic compounds ( $\mathrm{Yu}$ et al., 2009; Oleszczuk et al., 2012; Schindeman et al., 2012). Direct competition for adsorption sites is believed to occur primarily in small micropores of adsorbents where trace organics preferentially adsorb and can be blocked by NOM molecules that are small enough to access these adsorption sites (Chingombe et al., 2005; Agrafioti et al., 2013; Qian et al., 2015). Similarly, pore blockage, or pore constriction, has been previously documented in studies where organic matter competition reduced the intraparticle adsorption kinetic rates of micropollutants to biochar (Chen et al., 2007; Yu et al., 2009; Ahmad et al., 2014; Oh and Seo, 2015; Ulrich et al., 2015; Shimabuku et al., 2016). This competition mechanism results from larger organic particles that cannot directly access small micropore sites, but it can effectively block internal adsorption pathways that aid in adsorption of smaller micropollutants (Kong et al., 2011; Jung et al., 2013; Mohan et al., 2014).

The breakthrough curve of the wastewater control experiment indicates that a fraction of hydrophobic TCS molecules can be removed from wastewater through surface adsorption to wastewater solids themselves, which accumulated in the columns during operation (Supplementary Fig. S3). Adsorption to wastewater solids was expected due to numerous studies that have reported adsorption of TCS to organic matter and subsequent aqueous-phase removal in wastewater treatment processes such as activated sludge (McAvoy et al., 2002; Singer et al., 2002; Bester, 2003; Heidler and Halden, 2007; Lozano et al., 2013). Water quality parameters and wastewater characteristics for secondary effluent wastewater used in adsorption experiments are shown in Supplementary Tables S2-S5.
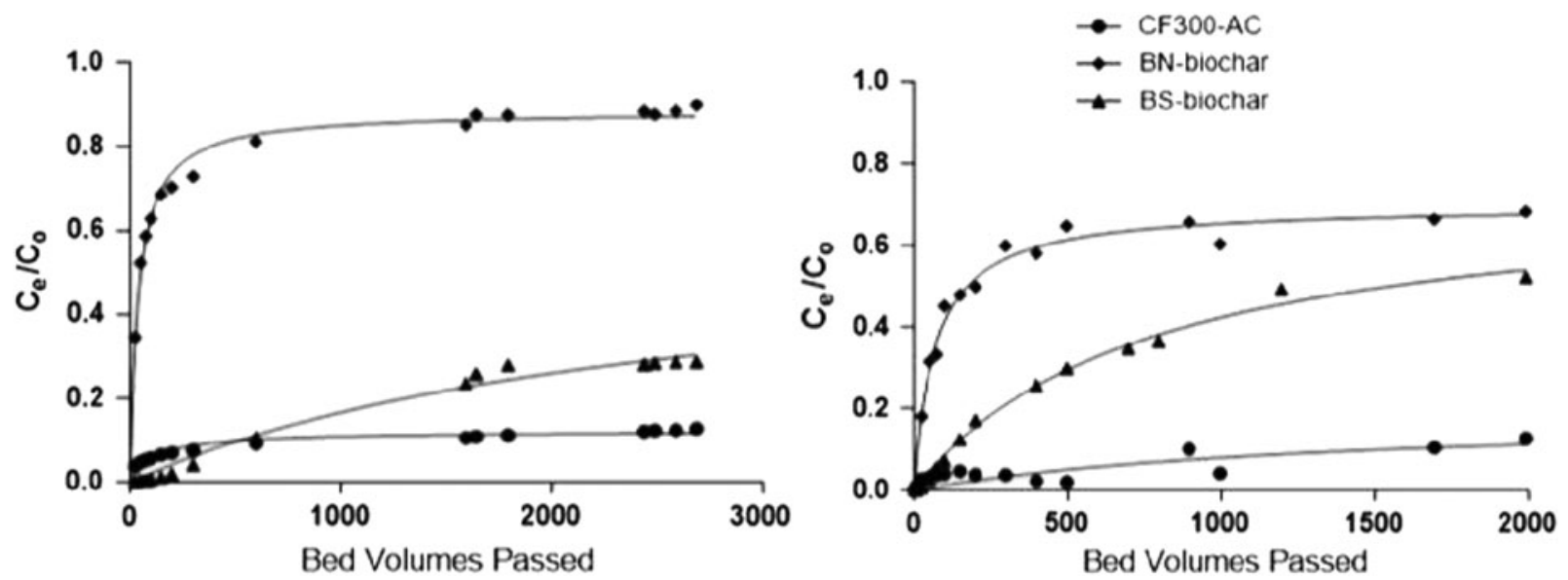

FIG. 5. Impact of adsorbent material (CF300-AC, BS-biochar, and BN-biochar) on TCS removal from Milli-Q water (figure on left) and wastewater (figure on right). Experiments were conducted at $\mathrm{pH} 7$ with a flow rate of $10 \mathrm{~mL} / \mathrm{min}$. TCS was added to Milli-Q water at $\sim 500 \mu \mathrm{g} / \mathrm{L}$. CF300-AC, activated carbon; BS-biochar, biosolids-derived biochar; BNbiochar, pine wood-derived biochar. 
Table 2. Physical Characteristics of Adsorbents

\begin{tabular}{lcccc}
\hline & $\begin{array}{c}\text { BET } \\
\text { surface } \\
\text { area } \\
\left(\mathrm{m}^{2} / \mathrm{g}\right)\end{array}$ & $\begin{array}{c}\text { Total pore } \\
\text { volume } \\
\left(\mathrm{cm}^{3} / \mathrm{g}\right)\end{array}$ & $\begin{array}{c}\text { Average } \\
\text { pore } \\
\text { radius }(\AA)\end{array}$ & $\begin{array}{c}\text { Total } \\
\text { micropore } \\
\text { volume } \\
\left(\mathrm{cm}^{3} / \mathrm{g}\right)\end{array}$ \\
\hline BS-biochar & 182 & 0.0874 & 2.83 & 0.0778 \\
BN-biochar & 44 & 0.0229 & 1.88 & 0.0184 \\
CF300-AC & 698 & 0.3217 & 4.64 & 0.3208 \\
\hline
\end{tabular}

BET, Brunauer-Emmett-Teller.

\section{Comparison of BS-biochar to commercial adsorbents}

Impact of adsorbent on TCS removal. TCS removal was highest with activated carbon (CF300-AC), followed by BSbiochar, and then BN-biochar in Milli-Q water (Fig. 5). Corresponding $C_{\mathrm{e}} / C_{\mathrm{o}}$ max and Kc values (Table 1) indicate that the BN-biochar adsorbent approached saturation more quickly compared with CF300-AC and BS-biochar. Mass breakthrough of TCS was reached quickest for BN-biochar, and CF300-AC outperformed BS-biochar.

Similar to Milli-Q experiments, TCS removal was highest with CF300-AC, and BS-biochar removed TCS more efficiently compared with BN-biochar in secondary wastewater effluent (Fig. 5). TCS removal with BS-biochar decreased by $50 \%$ in secondary effluent compared with removal from Milli-Q water, whereas TCS removal with CF300-AC decreased by $\sim 25 \%$. Alternatively, TCS removal from wastewater with $\mathrm{BN}$-biochar increased by $86 \%$ compared with Milli-Q water, and it resulted in an increase in bed volumes treated before mass breakthrough in column effluent. The increase in TCS removal for BN-biochar in wastewater compared with in Milli-Q water could be attributed to the accumulation of wastewater solids in the filter bed that sorbed additional TCS molecules.

$C_{\mathrm{e}} / C_{\mathrm{o}}$ max values for BS-biochar and $\mathrm{BN}$-biochar were similar for wastewater experiments; however, the BS-biochar demonstrated consistently higher removal rates and slower saturation of adsorption sites compared with BN-biochar. The low $C_{\mathrm{e}} / C_{\mathrm{o}}$ max value and poor model fit for CF300-AC suggests that the TCS adsorptive capacity was not approached. These findings are consistent with previous results from batch equilibrium experiments where more than $250 \mathrm{mg} / \mathrm{g}$ TCS was sorbed to activated carbon (Oh and Seo, 2015). Similarly, the Kc values indicate that more bed volumes can be treated with BS-biochar before reaching saturation compared with $\mathrm{BN}$-biochar. The CF300-AC yielded the highest observed Kc value (1,340 bed volumes, Table 1).
Characterization of BS-biochar and commercial adsorbents. TCS removal using BS-biochar produced in this study was compared with two commercial adsorbents made from different feedstocks. The results of the surface area analysis, including total BET surface area $\left(\mathrm{m}^{2} / \mathrm{g}\right)$, total pore volume $\left(\mathrm{cm}^{3} / \mathrm{g}\right)$, total micropore volume $\left(\mathrm{cm}^{3} / \mathrm{g}\right)$, and average pore radius $(\AA)$, are included in Table 2 (characterization was conducted on one representative sample for BSbiochar, BN-biochar, and CF300-AC). The CF300-AC had the highest overall surface area, total pore volume, and total micropore volume. The BS-biochar produced in this study was pyrolyzed at $600^{\circ} \mathrm{C}$ in a muffle furnace, and the $\mathrm{BN}$ biochar was commercially produced by slow pyrolysis using a kiln-based approach that can achieve temperatures above $600^{\circ} \mathrm{C}$. Differences in feedstock and biochar production technique can alter biochar chemical and physical properties and carbon stability, thus altering the potential for adsorption of micropollutants (Qian et al., 2015; Rajapaksha et al., 2016).

Surface morphology for each adsorbent used in column adsorption experiments was visualized by using SEM imaging (Fig. 6). The CF300-AC appeared to be more porous compared with the BS-biochar and BN-biochar. In addition, the pore structure of the BS-biochar produced in this study appears to be more heterogeneous compared with $\mathrm{BN}$ biochar, but it lacks the larger pores visible on the CF300AC. The large pores and highly irregular surface morphology of the activated carbon are characteristic of coal-derived carbonaceous adsorbents, which are typically produced through energy-intensive thermal activation processes, including high temperatures and steam (Bhatnagar et al., 2013; Thompson et al., 2016). The increased number of irregular surfaces and larger pores on the activated carbon surface increase the specific surface area, thus increasing the adsorption capacity for organic micropollutants such as TCS. Moles of TCS sorbed normalized to surface area are shown in Supplementary Table S6. Interestingly, BN-BC biochar had the highest amount of TCS sorbed per $\mathrm{m}^{2}$ sorbent. The surface area is so low on BN-BC biochar; however, that total sorption was the lowest. Even though CF300-AC had a low ratio of TCS sorbed per area, the total surface area was so high that TCS sorption was greatest corroborating that sorption capacity increases with increased total surface area.

FTIR analysis was used to elucidate functional groups on the surface of the adsorbents used in this study (Supplementary Fig. S4). BS-biochar produced in this study appeared to have a broad band present at $1,200 \mathrm{~cm}^{-1}$, which is associated with $\mathrm{C}-\mathrm{O}$ bonds, and could have contributed to
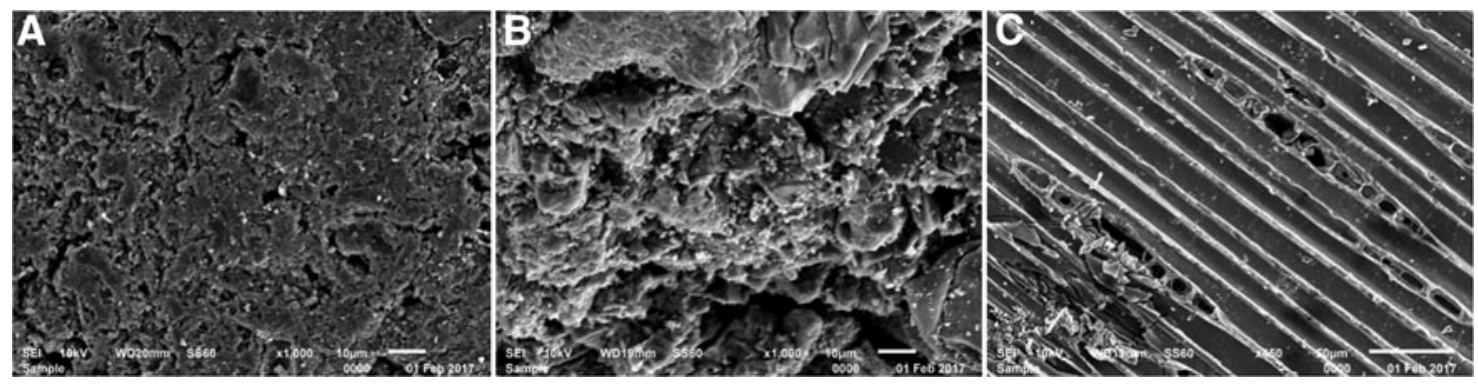

FIG. 6. Scanning electron microscope images of adsorbents. (A) BS-biochar, (B) CF300-AC, and (C) BN-biochar. (A) and (B) are at 1,000 $\times$ magnification, whereas (C) is shown at $450 \times$ for clarity. 
increased TCS adsorption compared with BN-biochar. Similarly, a study performed by Leng et al. (2015a) reported that biochars produced from sewage sludge were abundant in surface functional groups such as carboxyl, lactonic, and phenolic groups that aided in adsorption of an organic dye compound, Malachite green. In addition, studies have positively correlated oxygen-containing functional group abundance with the uptake of cationic Malachite green from solution (Leng et al., 2015a, 2015b). The BS-biochar and BNbiochar have broad bands present at $1,700 \mathrm{~cm}^{-1}$, which may be associated with $\mathrm{C}=\mathrm{O}$ groups in lactones and carboxylic anhydrides (Gasco et al., 2005). Previous research has suggested that BS-biochar (similar to the BS-biochar produced in this study) contains $\mathrm{C}-\mathrm{O}$ bonds on the surface, such as those found in phenols, esters, and carboxylic functional groups (Gasco et al., 2005; Tong et al., 2016). Polar oxygen-containing functional groups such as carboxyl and phenol groups likely interacted with phenyl groups on TCS molecules via hydrogen bonding, and aromatic groups present on both the adsorbent and adsorbate surface may have also contributed to $\pi-\pi$ stacking (Lei et al., 2013; Tong et al., 2016).

\section{Summary}

During the past century, the quantity of sludge produced from municipal WRRFs has greatly increased due to industrialization and urbanization (Smith et al., 2009; Lozano et al., 2012). Disposal of sludge and biosolids in landfills is a common practice because of its ease and low cost, but it is not a sustainable method of disposal due to concerns related to pollution and lack of material recovery (Hadi et al., 2015; McNamara et al., 2016). In recent years, modification and reuse of biosolids as a valuable adsorbent for the removal of contaminants has emerged as one of the most popular techniques for sludge processing for beneficial reuse (Agrafioti et al., 2013; Inyang and Dickenson, 2015; Qian et al., 2015; Xie et al., 2015; Tong et al., 2016). Implementing biosolids reuse practices, such as producing adsorbents, could provide multiple benefits to WRRFs through minimization of biosolids sent to landfills for disposal and increased removal of contaminants before discharge to receiving waters.

Results presented in this study demonstrated that BSbiochar effectively removed TCS from water and wastewater solutions. TCS removal was reduced due to competitive adsorption effects from other organic micropollutants (E2, SMX) and inorganic nutrients $\left(\mathrm{NH}_{4}{ }^{+}, \mathrm{PO}_{4}{ }^{3-}\right)$. In addition, BS-biochar effectively removed TCS from secondary wastewater effluent, but removal was decreased relative to Milli-Q. CF300-AC exhibited the highest TCS removal $(1,400 \mu \mathrm{g} / \mathrm{g})$, whereas BS-biochar sorbed up to $1,330 \mu \mathrm{g} / \mathrm{g}$ from Milli-Q. The TCS concentrations used in this study are much higher than in actual WRRF effluents, and there could be physical, practical, and economical limitations for wastewater applications wherein TCS concentrations are much lower. These constraints must be evaluated for specific scenarios of interest; however, this study serves as a proof of concept that BS-biochar could be implemented as a tertiary treatment to adsorb TCS, and potentially other similar micropollutants such as E2 and SMX, in WRRF effluents. In addition, previous research has demonstrated that spent BS-biochar adsorbents could be re-pyrolyzed to remove micropollutants including TCS, triclocarban, and nonylphenol (Ross et al., 2016). Future studies should be conducted to determine the effect of using repyrolyzed BS-biochar adsorbents on TCS and micropollutant adsorption from wastewater and to understand practical limitations.

Implementation of biochar as a tertiary wastewater treatment process could help mitigate the amount of organic micropollutants and other unregulated contaminants that are discharged to the environment from WRRF effluents. Developing sustainable treatment technologies that enhance the removal of organic micropollutants should be considered of high importance for WRRFs, especially in areas where receiving waters are sensitive ecosystems or have large populations downstream that rely on the same sources of water for potable water supplies. Recent life cycle assessment of BS-biochar production indicated that the energy input required for biosolids drying is a major expense (Thompson et al., 2016); accordingly, biochar production from biosolids would be more economically feasible for WRRFs with existing biosolids drying processes (McNamara et al., 2016). Future research should be conducted while using BS-biochar adsorbents in pilot-scale contactors to determine the feasibility of implementing BSbiochar filtration processes as a tertiary treatment technology for WRRFs.

\section{Acknowledgments}

The authors wish to thank the Marquette University Innovation Fund for funding this study. They would also like to thank Mr. Matthew Magruder from Milwaukee Metropolitan Sewerage District for his guidance throughout the project.

\section{Author Disclosure Statement}

No competing financial interests exist.

\section{References}

Agrafioti, E., Bouras, G., Kalderis, D., and Diamadopoulos, E. (2013). Biochar production by sewage sludge pyrolysis. $J$. Anal. Appl Pyrolysis 101, 72.

Ahmad, M., Lee, S.S., Dou, X., Mohan, D., Sung, J.K., Yang, J.E., and Ok, Y.S. (2012). Effects of pyrolysis temperature on soybean stover- and peanut shell-derived biochar properties and TCE adsorption in water. Bioresour. Technol. $118,536$.

Ahmad, M., Rajapaksha, A.U., Lim, J.E., Zhang, M., Bolan, N., Mohan, D., and Ok, Y.S. (2014). Biochar as a sorbent for contaminant management in soil and water: A review. Chemosphere 99, 19.

American Public Health Association (APHA). (1975). Standard Methods for Examination of Water and Wastewater. 20th edition. Washington, DC: APHA.

American Society of Testing Materials (ASTM). (2013). Standard Practice for the Prediction of Contaminant Adsorption on GAC in Aqueous Systems Using Rapid Small-Scale Column Tests. Vol. 3. West Conshohocken, PA: ASTM International.

Barbosa, A.E., Fernandes, J.N., and David, L.M. (2012). Key issues for sustainable urban stormwater management. Water Res. 46, 6787.

Behera, S.K., Oh, S.Y., and Park, H.S. (2010). Sorption of triclosan onto activated carbon, kaolinite and montmorillonite: 
Effects of $\mathrm{pH}$, ionic strength, and humic acid. J. Hazard. Mater. 179, 684.

Bernhardt, E.S., Band, L.E., Walsh, C.J., Berke, P.E., Carey, R.O., Hochmuth, G.J., and Hunt, W.F. (2012). A method for the evaluation of pollution loads from urban areas at river basin scale. Water Res. 135, 6609.

Bester, K. (2003). Triclosan in a sewage treatment processbalances and monitoring data. Water Res. 37, 3891.

Bhatnagar, A., Hogland, W., Marques, M., and Sillanpää, M. (2013). An overview of the modification methods of activated carbon for its water treatment applications. Chem. Eng. J. 219, 499.

Blair, B.D., Crago, J.P., Hedman, C.J., and Klaper, R.D. (2013). Pharmaceuticals and personal care products found in the Great Lakes above concentrations of environmental concern. Chemosphere 93, 2116.

Blánquez, P., and Guieysse, B. (2008). Continuous biodegradation of $17 \beta$-estradiol and $17 \alpha$-ethynylestradiol by Trametes versicolor. J. Hazard. Mater. 150, 459.

Cao, X., and Harris, W. (2010). Properties of dairy-manurederived biochar pertinent to its potential use in remediation. Bioresour. Technol. 101, 5222.

Carballa, M., Omil, F., Ternes, T., and Lema, J.M. (2007). Fate of pharmaceutical and personal care products (PPCPs) during anaerobic digestion of sewage sludge, Water Res. 41, 2139.

Carey, D.E., and McNamara, P.J. (2015). The impact of triclosan on the spread of antibiotic resistance in the environment. Front. Microbiol. 5, 780.

Carey, D.E., and McNamara, P.J. (2016). Altered antibiotic tolerance in anaerobic digesters acclimated to triclosan or triclocarban. Chemosphere 163, 22.

Carey, D.E., McNamara, P.J., and Zitomer, D.H. (2015). Biochar from pyrolysis of biosolids for nutrient adsorption and turfgrass cultivation. Water Environ. Res. 87, 2098.

Carey, D.E., Zitomer, D.H., Kappell, A.D., Choi, M.J., Hristova, K.R., and McNamara, P.J. (2016). Chronic exposure to triclosan sustains microbial community shifts and alters antibiotic resistance gene levels in anaerobic digesters. Environ. Sci. Proc. Imp. 18, 1060.

Chen, J., Zhu, D., and Sun, C. (2007). Effect of heavy metals on the sorption of hydrophobic organic compounds to wood charcoal. Environ. Sci. Technol. 41, 2536.

Chingombe, P., Saha, B., and Wakeman, R.J. (2005). Surface modification and characterization of a coal-based activated carbon. Carbon 43, 3132.

Crittenden, J.C., Reddy, P.S., Arora, H., Trynoski, J., Hand, W., Perram, D.L., and Summers, R.S. (1991). Rapid small-scale column tests. Am. Water Works Assoc. 83, 77.

Ellis, J.B. (2006). Pharmaceutical and personal care products (PPCPs) in urban receiving waters. Environ. Pollut. 144, 184.

Environmental Protection Agency (EPA). (2017). Drinking Water Treatability Database: Granular Activated Carbon. Washington, DC: Environmental Protection Agency. Available at: www .iaspub.epa.gov/tdb/pages/treatment/treatmentOverview.do (accessed January 1, 2017).

Foran, C.M., Bennett, E.R., and Benson, W.H. (2000). Developmental evaluation of a potential non-steroidal estrogen: Triclosan. Mar. Environ. Res. 50, 153.

Fritsch, E.B., Connon, R.E., Werner, I., Davies, R.E.U.E., Beggel, S., Feng, W., and Pessah, I.N. (2013). Triclosan impairs swimming behavior and alters expression of excitation contraction coupling proteins in fathead minnow (Pimephales promelas). Environ. Sci. Technol. 47: 2008.
Gasco, G., Mendez, A., and Gasco, J.M. (2005). Preparation of carbon-based adsorbents from sewage sludge pyrolysis to remove metals from water. Desalination 180, 245.

Gasperi, J., Zgheib, S., Cladière, M., Rocher, V., Moilleron, R., and Chebbo, G. (2012). Priority pollutants in urban stormwater: Part 2-case of combined sewers. Water Res. 46, 6693.

Hadi, P., Xu, M., Ning, C., Sze Ki Lin, C., and McKay, G. (2015). A critical review on preparation, characterization and utilization of sludge-derived activated carbons for wastewater treatment. Chem. Eng. J. 260, 895.

Heidler, J., and Halden, R.U. (2007). Mass balance assessment of triclosan removal during conventional sewage treatment. Chemosphere 66, 362.

Hoffman, T.C., Zitomer, D.H., and McNamara, P.J. (2016). Pyrolysis of wastewater biosolids significantly reduces estrogenicity. J. Hazard. Mater. 317, 579.

Inyang, M., and Dickenson, E. (2015). The potential role of biochar in the removal of organic and microbial contaminants from potable and reuse water: A review. Chemosphere 134, 232.

Jung, C., Park, J., Lim, K.H., Park, S., Heo, J., Her, N., and Yoon, Y. (2013). Adsorption of selected endocrine disrupting compounds and pharmaceuticals on activated biochars. $J$. Hazard. Mater. 263, 702.

Kearns, J.P., Wellborn, L.S., Summers, R.S., and Knappe, D.R.U. (2014). 2,4-D adsorption to biochars: Effect of preparation conditions on equilibrium adsorption capacity and comparison with commercial activated carbon literature data. Water Res. 62, 29.

Kidd, K.A., Blanchfield, P.J., Mills, K.H., Palace, V.P., Evans, R.E., Lazorchak, J.M., and Flick, R.W. (2007). Collapse of a fish population after exposure to a synthetic estrogen. Proc. Natl. Acad. Sci. U S A. 104, 8897.

Kimura, K., Amy, G., Drewes, J.E., Heberer, T., Kim, T.U., and Watanabe, Y. (2003). Rejection of organic micropollutants (disinfection by-products, endocrine disrupting compounds, and pharmaceutically active compounds) by NF/RO membranes. J. Membr. Sci. 227, 113.

Knappe, D.R.V., Snoeyink, V.L., Roche, P., Prados, M.J., and Bourbigot, M.M. (1997). Effect of preloading on rapid smallscale column test predictions of atrazine removal by GAC adsorbers. Wat. Res. 31, 11.

Kolpin, D.W., Furlong, E.T., Meyer, M.T., Thurman, E.M., Zaugg, S.D., Barber, L.B., and Buxton, H.T. (2002). Pharmaceuticals, hormones, and other organic wastewater contaminants in U.S. Streams, 1999-2000: A national reconnaissance. Environ. Sci. Technol. 36, 1202.

Kong, H., He, J., Gao, Y., Wu, H., and Zhu, X. (2011). Cosorption of phenanthrene and mercury(II) from aqueous solution by soybean stalk-based biochar. J. Agric. Food Chem. 59, 12116.

Lei, C., Hu, Y.Y., and He, M.Z. (2013). Adsorption characteristics of triclosan from aqueous solution onto cetylpyridinium bromide (CPB) modified zeolites. Chem. Eng. J. 219, 361.

Leng, L., Yuan, X., Huang, H., and Zeng, G. (2015a). Bio-char derived from sewage sludge by liquefaction: Characterization and application for dye adsorption. Appl. Surf. Sci. 346, 223.

Leng, L., Yuan, X., Zeng, G., Shao, J., Chen, X., Wu, Z., Wang, H., and Peng, X. (2015b). Surface characterization of rice husk bio-char produced by liquefaction and application for cationic dye (Malachite green) adsorption. Fuel 155, 77.

Lindström, A., Buerge, I.J., Poiger, T., Bergqvist, P.A., Müller, M.D., and Buser, H.R. (2002). Occurence and environmental 
behaviour of the bactericide triclosan and its methyl derivative in surface waters and waste water. Environ. Sci. Technol. 36, 2322.

Lozano, N., Rice, C.P., Ramirez, M., and Torrents, A. (2012). Fate of triclosan and methyltriclosan in soil from biosolids application. Environ. Pollut. 160, 103.

Lozano, N., Rice, C.P., Ramirez, M., and Torrents, A. (2013). Fate of triclocarban, triclosan and methyltriclosan during wastewater and biosolids treatment processes. Water Res. 47, 4519.

Manda, B.M.K., Worrell, E., and Patel, M.K. (2014). Innovative membrane filtration system for micropollutant removal from drinking water-prospective environmental LCA and its integration in business decisions. J. Clean. Prod. 72, 153.

McAvoy, D.C., Schatowitz, B., Jacob, M., Hauk, A., and Eckhoff, W.S. (2002). Measurement of triclosan in wastewater treatment systems. Environ. Toxicol. Chem. 21, 1323.

McMurry, L.M., Oethinger, M., and Levy, S.B. (1998). Triclosan targets lipid synthesis. Nature 394, 531.

McNamara, P.J., Koch, J.D., Liu, Z., and Zitomer, D.H. (2016). Pyrolysis of dried wastewater biosolids can be energy positive. Water Environ. Res. 88, 804.

McNamara, P.J., and Levy, S.B. (2016). Triclosan: An instructive tale. Antimicrob. Agents Chemother. 60, 7015.

Mohan, D., Sarswat, A., Ok, Y.S., and Pittman, C.U. (2014). Organic and inorganic contaminants removal from water with biochar, a renewable, low cost and sustainable adsorbent-a critical review. Bioresour. Technol. 160, 191.

Monsalvo, V.M., Mohedano, A.F., and Rodriguez, J.J. (2011). Activated carbons from sewage sludge. Application to aqueousphase adsorption of 4-chlorophenol. Desalination 277, 377.

Nam, S.W., Choi, D.-J., Kim, S.K., Her, N., and Zoh, K.D. (2014). Adsorption characteristics of selected hydrophilic and hydrophobic micropollutants in water using activated carbon. J. Hazard. Mater. 270, 144.

Nghiem, L.D., and Coleman, P.J. (2008). NF/RO filtration of the hydrophobic ionogenic compound triclosan: Transport mechanisms and the influence of membrane fouling. Sep. Purif. Technol. 62, 709.

Nowotny, N., Bernhard, E., von Sonntag, C., and Fahlenkamp, H. (2007). Quantification and modeling of the elimination behavior of ecologically problematic wastewater micropollutants by adsorption on powdered and granulated activated carbon. Environ. Sci. Technol. 41, 2050.

Oh, S.-Y., and Seo, Y.-D. (2015). Sorption of halogenated phenols and pharmaceuticals to biochar: Affecting factors and mechanisms. Environ. Sci. Pollut. Res. 23, 951.

Oleszczuk, P., Hale, S.E., Lehmann, J., and Cornelissen, G. (2012). Activated carbon and biochar amendments decrease pore-water concentrations of polycyclic aromatic hydrocarbons (PAHs) in sewage sludge. Bioresour. Technol. 111, 84.

Orvos, D.R., Versteeg, D.J., Inauen, J., Capdevielle, M., Rothenstein, A., and Cunningham, V. (2002). Aquatic toxicity of triclosan. Environ. Toxicol. Chem. 21, 1338.

Otero, M., Rozada, F., Calvo, L.F., García, A.I., and Morán, A. (2003). Elimination of organic water pollutants using adsorbents obtained from sewage sludge. Dyes Pigments 57, 55.

Pal, A., He, Y., Jekel, M., Reinhard, M., and Gin, K.Y.H. (2014). Emerging contaminants of public health significance as water quality indicator compounds in the urban water cycle. Environ. Int. 71, 46.

Pitt, R., Field, R., Lalor, M., and Brown, M. (1995). Urban stormwater toxic pollutants: Assessment, sources, and treatability. Water Environ. Res. 67, 260.
Qian, K., Kumar, A., Zhang, H., Bellmer, D., and Huhnke, R. (2015). Recent advances in utilization of biochar. Renew. Sust. Energy Rev. 42, 1055.

Rajapaksha, A.U., Chen, S.S., Tsang, D.C.W., Zhang, M., Vithanage, M., Mandal, S., and Ok, Y.S. (2016). Engineered/ designer biochar for contaminant removal/immobilization from soil and water: Potential and implication of biochar modification. Chemosphere 148, 276.

Reddy, K.R., Asce, F., Xie, T., and Dastgheibi, S. (2014). Evaluation of biochar as a potential filter media for the removal of mixed contaminants from urban storm water runoff. J. Environ. Eng. 140, 1.

Roberts, K.G., Gloy, B.A., Joseph, S., Scott, N.R., and Lehmann, J. (2010). Life cycle assessment of biochar systems: Estimating the energetic, economic, and climate change potential. Environ. Sci. Technol. 44, 827.

Ross, J.J., Zitomer, D.H., Miller, T.R., Weirich, C.A., and McNamara, P.J. (2016). Emerging investigators series: Pyrolysis removes common microconstituents triclocarban, triclosan, and nonylphenol from biosolids. Environ. Sci. Water Res. Technol. 2, 282.

Rozada, F., Otero, M., Parra, J.B., Morán, A., and García, A.I. (2005). Producing adsorbents from sewage sludge and discarded tyres: Characterization and utilization for the removal of pollutants from water. Chem. Eng. J. 114, 161.

Schindeman, L., Strathmann, T., Metz, D., Isabel, R.S., and Cummings, J. (2012). Evaluating GAC Filters for Control of DBP Precursors and Trace Organic Contaminants, Water Research Foundation Report, 4101. Denver, CO: Water Research Foundation.

Schwarzenbach, R., Gschwend, P., and Imboden, D. (2003). Environmental Organic Chemistry: Second Edition. Hoboken, NJ: John Wiley and Sons, Inc.

Seib, M.D., Berg, K.J., and Zitomer, D.H. (2016). Reduced energy demand for municipal wastewater recovery using an anaerobic floating filter membrane bioreactor. Environ. Sci. Water Res. Technol. 2, 290.

Shimabuku, K.K., Kearns, J.P., Martinez, J.E., Mahoney, R.B., Moreno-Vasquez, L., and Summers, R.S. (2016). Biochar sorbents for sulfamethoxazole removal from surface water, stormwater, and wastewater effluent. Water Res. 96, S60.

Singer, H., Muller, S., Tixier, C., and Pillonel, L. (2002). Triclosan: occurrence and fate of a widely used biocide in the aquatic environment: Field measurements in wastewater treatment plants, surface waters and lake sediments. Environ. Sci. Technol. 36, 4998.

Smith, K.M., Fowler, G.D., Pullket, S., and Graham, N.J.D. (2009). Sewage sludge-based adsorbents: A review of their production, properties and use in water treatment applications. Water Res. 43, 2569.

Stasinakis, A.S., Mamais, D., Thomaidis, N.S., Danika, E., Gatidou, G., and Lekkas, T.D. (2008). Inhibitory effect of triclosan and nonylphenol on respiration rates and ammonia removal in activated sludge systems. Ecotoxicol. Environ. Saf. 70, 199.

Tan, X., Liu, Y., Zeng, G., Wang, X., Hu, X., Gu, Y., and Yang, Z. (2015). Application of biochar for the removal of pollutants from aqueous solutions. Chemosphere 125, 70.

Thompson, K.A., Shimabuku, K.K., Kearns, J.P., Knappe, D.R.U., Summers, R.S., and Cook, S.M. (2016). Environmental comparison of biochar and activated carbon for tertiary wastewater treatment. Environ. Sci. Technol. 50, 11253.

Tohidi, F., and Cai, Z. (2017). Fate and mass balance of triclosan and its degradation products: Comparison of three 
different types of wastewater treatments and aerobic/anaerobic sludge digestion. J. Hazard. Mater. 323, 329.

Tong, Y., Mayer, B.K., and McNamara, P. (2016). Triclosan adsorption using wastewater biosolids-derived biochar. Environ. Sci Water Res. Technol. [Epub ahead of print]; DOI: 10.1039/c6ew00127k.

Tong, Y., McNamara, P.J., and Mayer, B.K. (2017). Fate and impacts of triclosan, sulfamethoxazole, and $17 \beta$-estradiol during nutrient recovery via ion exchange and struvite precipitation. Environ. Sci. Water Res. Technol. [Epub ahead of print]; DOI: 10.1039/C7EW00280G.

Uchimiya, M., Lima, I.M., Klasson, K.T., and Wartelle, L.H. (2010). Contaminant immobilization and nutrient release by biochar soil amendment: Roles of natural organic matter. Chemosphere 80, 935.

Ulrich, B.A., Im, E.A., Werner, D., and Higgins, C.P. (2015). Biochar and activated carbon for enhanced trace organic contaminant retention in stormwater infiltration systems. Environ. Sci. Technol. 49, 6222.

Xie, T., Reddy, K.R., Wang, C., Yargicoglu, E., and Spokas, K. (2015). Characteristics and applications of biochar for environmental remediation: A review. Crit. Rev. Environ. Sci Technol. 45, 939.

Yao, H., Lu, J., Wu, J., Lu, Z., Wilson, P.C., and Shen, Y. (2013). Adsorption of fluoroquinolone antibiotics by wastewater sludge biochar: Role of the sludge source. Water Air Soil Pollut. 224, 1370.

Yao, Y., Gao, B., Chen, J., and Yang, L. (2013). Engineered biochar reclaiming phosphate from aqueous solutions: Mechanisms and potential application as a slow-release fertilizer. Environ. Sci. Technol 47, 8700.
Yao, Y., Gao, B., Inyang, M., Zimmerman, A.R., Cao, X., Pullammanappallil, P., and Yang, L. (2011). Removal of phosphate from aqueous solution by biochar derived from anaerobically digested sugar beet tailings. J. Hazard. Mater. 190, 501.

Ying, G.G., and Kookana, R.S. (2007). Triclosan in wastewaters and biosolids from Australian wastewater treatment plants. Environ. Int. 33, 199.

Yu, L., and Zhong, Q. (2006). Preparation of adsorbents made from sewage sludges for adsorption of organic materials from wastewater. J. Hazard. Mater. 137, 359.

Yu, Z., Peldszus, S., and Huck, P.M. (2009). Adsorption of selected pharmaceuticals and an endocrine disrupting compound by granular activated carbon. 2. Model prediction. Environ. Sci. Technol. 43, 1474.

Zerzghi, H., Gerba, C.P., Brooks, J.P., and Pepper, I.L. (2010). Long-term effects of land application of class B biosolids on the soil microbial populations, pathogens, and activity. $J$. Environ. Qual. 39, 402.

Zgheib, S., Moilleron, R., and Chebbo, G. (2012). Priority pollutants in urban stormwater: Part 1-case of separate storm sewers. Water Res. 46, 6683.

Zhu, X., Liu, Y., Luo, G., Qian, F., Zhang, S., and Chen, J. (2014). Facile fabrication of magnetic carbon composites from hydrochar via simultaneous activation and magnetization for triclosan adsorption. Environ. Sci. Technol. 48, 5840 .

Zietzschmann, F., Muller, J., Sperlich, A., Ruhl, A.S., Meinel, F., Altmann, J., and Jekel, M. (2014). Rapid small-scale column testing of granular activated carbon for organic micro-pollutant removal in treated domestic wastewater. Water Sci. Technol. 70, 1271. 